\title{
Prenatal Development of the Nostril in Rabbit (Oryc- mtolagus cuniculus)
}

\section{Saleh A. M. A. ALomaisi ${ }^{1,2 *}$, Hanaa M. El-Ghazali ${ }^{2}$, Hamed M. Nosseur'2, Salah El-dein A. Ahmed ${ }^{2}$, Mervat M. Konsowa ${ }^{2}$}

${ }^{1}$ Department of Animal Research, Regional Research Station, Agriculture Research and Extension Authority. 87148 Thamar Yemen.

${ }^{2}$ Department of Anatomy and Embryology, Faculty of Veterinary Medicine, Zagazig University, 44511, Egypt. Paper extracted from PH.D. thesis of Saleh Ahmed Mohammed Ali Al-Omaisi

\section{Abstract}

This work aimed to throw more lights on beginning time of the first appearance and origin as well developmental vicissitudes of rabbit's nostril. This work was carried out on 116 rabbit embryos and fetuses of both sexes. The specimens were obtained, from 14 normal and apparently healthy adult female rabbit. At days (D) 11 there was a cleared invagination on the thickened epithelium of the nasal placode as a nasal pit. The latter had an oval in outline at $12 \mathrm{D}$ and it formed the nasal sac. At $13 \mathrm{D}$ the nasal sac had given rise to the primitive nasal cavity. Its external opening will differentiate to form the primitive nostril, occluded by nasal plug. At $14 \mathrm{D}$ the lining epithelium of the lateral nasal wall was of variable thickness of stratified cuboidal type of epithelium.
At $16 \mathrm{D}$ there were a clear some cellular apoptosis in center of nasal plug.

At 18-20 D the center of the nasal plug was dissoluted and the nostril was begun to canalize. At $22 \mathrm{D}$ the nostril was lined by keratinized stratified squamous epithelium especially at the rostral part of nasal vestibule and the nasal vestibule was lined by thick keratinized stratified squamous epithelium. At $30 \mathrm{D}$ the nostrils appeared as oblique slit like opening similar to that of newly born rabbit.

Keywords: Nasal placode, pit, sac, plug, rostral naris

\section{Introduction}

The nostril is the portal entry to the nasal cavity. In rabbit, Beaudoin, et al., (2003) revealed that, at 12.5 
days, the face is modeled, developing nasal, maxillary and mandibular buds. Roongruangchai et al., (2006) added that, at 12-14 $\mathrm{mm}$ rabbit embryo the nasal pit is surrounded by the lateral and medial nasal prominences. In rat, Vidic (1971) and Vidic, et al., (1972) observed that, the nasal placodes become visible at $9^{\text {th }}$ and $12^{\text {th }}$ days of gestation respectively. In human, Warbrick (1960) revealed that, the broad opening of the stomatodaeum is bounded caudally by the mandibular arch, laterally by the maxillary processes and rostrally by the prominent, overhanging front part of the head. A wide shallow concavity in the roof of the stomatodaeum continues forwards and upwards over the front of the head. Arey (1974) and Snell (1975) mentioned that, the nostrils of the human embryo are closed by epithelial plugs from the second to the sixth month. Kumoi, et al., (1993) stated that, the complete recanalization of the nasal plug in human occurs in 16-17-week fetus. Nishimura (1993) observed that, the reabsorption of the temporary nasal epithelial plug at a 13 to 15-week human fetus. Sadler (2012) and Som and Naidich (2013) added that, Cavum nasi is initially indicated by the nasal placodes. The latter forming the nasal pits which are surrounded by the medial and lateral nasal prominences. The available literature revealed that the development of the nasal cavity in different domestic animals, are discussed in several animals such as; Seham-Gabr (2015) in rabbit, Shapiro (1970) in mice and rat, Gaare (1976); Gaare and Langman (1977) and Burk, et al., (1979) in mice, Roongruangchai, et al., (2006) in rabbit, pig and man, Warbrick (1960) Andersen and Matthiessen (1967), McGarth (1980), Kumoi, et al., (1993) and Som and Naidich (2013) in man and Ahmed (1988) in camel. Carlson (1981) in mammals, Noden and De Lahunta (1985) in domestic animals, Frandson, et al., (2009) and McGeady, et al. (2017) in animals. The aim of this work is to throw more lights on beginning time of first appearance and origin as well as developmental vicissitudes of nostril of the rabbit.

\section{Material and Methods}

This work was carried out on 116 rabbit embryos and fetuses of both sexes. The specimens were obtained from 14 normal and apparently healthy adult female rabbit. The rabbits were obtained from the rabbit farm of Faculty of Agriculture, Zagazig University. They were housed for one week before experiment for acclimatization to standard pellet ration (El-Nasr Chemical Company, Cairo, Egypt) and were given free accesses to water ad libitum. All animals managed according to Animal Ethical 
Committee of Faculty of Veterinary Medicine, Zagazig University (ZUIACU/2/F/109/2018).

The pregnant rabbits were tested at age $11-30^{\text {th }}$ days of pregnancy. The age of embryo was estimated by the pregnancy records and age of pregnancy depended on the time of mating. Just after slaughtering, evisceration and evacuation of their uteri. The obtained embryos and fetuses were classified into two group representing the all ages of pregnancy. Group (A) were immersed as a whole in $10 \%$ neutral buffered formalin and the other group $(B)$ were immersed in Bouin's solution for 3-24 hours. Then washed carefully with distilled water and transferred to $70 \%$ ethyl alcohol. Then the specimens were subjected to the following techniques:

\section{Histological technique}

The heads of fetuses over 20 days were immersed in EDTA 5.5\% - 7.0 PH buffered, with sodium hydroxid and neutralized in $5 \%$ sodium sulphate. The time taken for decalcification depended on the age of fetuses. After all specimens assembled for normal histological technique, all specimens were dehydrated in ascending grades of alcohols, cleared in three changes of benzene and embedded in paraffin wax. Paraffin section of $5-7 \mu$ thickness were obtained and stained by Hematoxylin and Eosin (H\&E) stain for general histological demonstration Drury and Wallington (1980), Suvarna, et al., (2013). The slides were examined by using light microscopes and the observations were recorded.

\section{Scanning electron microscope}

The embryos and fetuses were delivered at hourly post conception. Embryos and fetuses were trimmed and fixed in glutaraldehyde for 12-24 hour and then post fixed in $1 \%$ osmium tetroxide for 90-120 min (Cheville and Stasko, 2014). The palates were dehydrated through an ascending concentration of ethyl alcohol followed by $2.5 \%$ buffered leave tissue overnight at $4^{\circ} \mathrm{C}$. glutaraldehyde + $2 \%$ paraformaldehyde, in $0.1 \mathrm{M}$ sodium phosphate buffer $\mathrm{pH}$ 7.4., wash $3 \times 15$ minutes (min.) in $0.1 \mathrm{M}$ sodium phosphate buffer $+0.1 \mathrm{M}$ Sucrose postfix 90 min. in $2 \%$ sodium phosphate buffered osmium tetroxide $\mathrm{pH} 7.4$, wash $3 \times 15 \mathrm{~min}$ in $0.1 \mathrm{M}$ sodium phosphate buffer $\mathrm{pH} 7.4$., dehydrate $2 \times 15 \mathrm{~min}$ : $50 \%$ ethanol (in distilled water). contrast overnight using $70 \%$ acetone $+0.5 \%$ uranyl acetate $+1 \%$ phosphotungstic acid at $4^{\circ}$ C., $2 \times 15 \mathrm{~min} .80 \%$ ethanol. $2 \times 15 \mathrm{~min} .90 \%$ ethanol. 2 x 15 min. $96 \%$ ethanol. 3 x 20 min. $100 \%$ ethanol. The specimens were coated with gold-palladium membranes and examined at EM Unit, Mansoura University, Egypt in a Jeol 
JSM-6510 L.V SEM. The microscope was operated at $30 \mathrm{KV}$.

The nomenclature used along the course of this study was those adopted by Nomina Anatomica Veterinaria (2017), Nomina Embryologica Veterinaria (2017) and Nomina Histologica Veterinaria (2017)

\section{Results}

Rabbit embryo of 11 days old: There was a clear invagination on the thickened epithelium of the nasal placode as a nasal pit (Fig.1A). The latter had an oval shape.

Rabbit embryo of 12 days old: The nasal pits which were oval in outline, became narrow from side to side. After that, ran caudally, slightly medially to form the nasal sac. The opened part of the nasal sac was bounded by a raised-up edge which form the lateral and medial nasal processes (Fig.1B). The latter processes were appeared as undifferentiated mesenchymel cells. The nasal sacs were detected as an ectodermal invagination lined with 5-8 cell layers. The nasal sac was still closed by cellular mass called nasal plug (Fig.1C). The primitive nasal septum appeared (Fig. 1D)

\section{Rabbit embryo of 13-14 days old:}

The nasal sacs had given rise to the primitive nasal cavity. Its external opening will differentiate to form the primitive rostral naris (Nostril) which is occluded by the nasal plug. The medial and lateral sides of the nostrils showed the miniature of nasal cartilages. The two nasal cavities were separated from each other by undifferentiated mesnchymal tissue forming the primary nasal septum (Figs $2 \mathrm{~A}$ and $\mathrm{B}$ ). The lining epithelium of the lateral nasal wall was of variable thickness of stratified cuboidal type.

Rabbit embryo of 16 days old: The nostril (Rostral naris) still occluded with epithelial nasal plug (Fig 2C). During this stage, there were clear some cellular apoptosis in the center of the nasal plug, marked by the appearance of irregular and numerous piknotic nuclei (Fig 2D).

Rabbit fetus of 18-20 days old: The center of the nasal plug was dissoluted and the nostril began to canalized (Fig.3A). Also, the lining epithelium of the nasal vestibule was lined by stratified squamous non-keratinized epithelium with clear basement membrane (Figs 3B, C and D).

Rabbit fetus of $\mathbf{2 2}$ days old: The nostril was lined by keratinized stratified squamous epithelium especially at the rostral part of the nasal vestibule (Fig 4A). The nasal vestibule was lined by thick keratinized stratified squamous epithelium. There were many submucosal glandular buds appeared as invagination of the 
aforementioned lining epithelium (Fig 4B).

Rabbit fetus of $\mathbf{3 0}$ day days old: The nostrils appeared as oblique slit like opening similar to that of newly born rabbit (Fig 4C). The nasal vestibule was lined by four to six cell layers of keratinized stratified squamous epithelium (Fig 4D).

\section{Discussion}

The present investigation showed that, the thickened epithelium of the nasal placode was invaginated to make the nasal pits (olfactory pits) in 11-days-old rabbit embryo, a result which came in agreement with, the statemens of Roongruangchai, et al., (2006) in rabbit and Cuschieri and Bannister (1975) in rat.

The nasal pits in the present work which were oval in outline, became narrow from side to side and ran caudally, slightly medially form the nasal sac. The opened part of the nasal sac was bounded by a raised-up edge which form the lateral and medial nasal processes. The latter processes were appeared as undifferentiated cells. The nasal sacs were detected as an ectodermal invagination lined with 5-8 cell layers in 12days-old embryo, a procedure that over resembling that mentioned by Beaudoin, et al., (2003), Roongruangchai, et al., (2006) and SehamGabr (2015) in rabbit, Vidic (1971)

J. Vet. Anat. and Vidic, et al., (1972) in rat,, Kumoi, et al., (1993), Mayor and Theveneau (2013) and Som and Naidich (2013) in human, Noden and De Lahunta (1985) in mammals and Frandson, et al., (2009) and McGeady, et al., (2017) in animals.

The present study revealed that, the nasal sac was still closed by cellular mass called the nasal plug and the primitive nasal septum appeared at 12-days-old rabbit embryo. These results were in agreement with the statement of Arey (1974) and Snell (1975) as they observed that, the nostrils of the human embryo were closed by epithelial plugs from the second to the sixth month. Kumoi, et al., (1993) in human, stated that the complete recanalization of the nasal plug occurred in 16-17-week-fetus. Nishimura (1993) observed that, the reabsorption of the temporary nasal epithelial plug at a 13 to 15 -week-human fetus. Ahmed (1988) in camel embryo revealed that, the nostrils were occluded with nasal plugs at 23 $\mathrm{mm}$ CVRL. While these results were conflicted with the statement of Seham-Gabr (2015) in rabbit whose claimed that, the rostral nares were occluded with nasal plug at 23- daysold rabbit embryo.

In the animal under investigation, at 13-days-old rabbit embryo, the nasal sacs had given rise to the primitive nasal cavity. Its external opening which will differentiate to form the 
rostral naris (Nostril) which was still occluded by nasal plug. The medial and lateral sides of the nostrils showed the miniature of nasal cartilages. The two nasal cavities were separated from each other's by undifferentiated mesnchymal tissue forming the primary nasal septum. These findings came parallel with Roongruangchai, et al., (2006) and Seham-Gabr (2015) in rabbit, Vidic (1971) and Valverde, et al., (1992) in rat, Kumoi, et al., (1993), Müller and O'Rahilly (2004), Mayor and Theveneau (2013) and Som and Naidich (2013), in human, Noden and De Lahunta (1985) in mammals and McGeady, et al., (2017) in animals.

in the current work, the nostril was lined by keratinized stratified squamous epithelium and nasal plug completely degenerated and disappeared at 22-days-old rabbit fetus. These results were conflicted with the statements of Seham-Gabr (2015) in rabbit whose mentioned that, the two rostral nares are occluded by epithelioid nasal plug at the age of 23 days before birth then recanalized by degeneration of their epithelium plugs at the age of 30 days, the $1^{\text {st }}$ day of birth.

\section{References}

Ahmed, S.A. (1988): Prenatal development of the upper respiratory tract of the camel (Camelus dromedarius).
Ph.D. Thesis. Anatomy and Embryology Department, Faculty of Veterinary Medicine, Zagazig.

Andersen, $H$. and Matthiessen, $M$. (1967): Histochemistry of the early development of the human central face and cavity with special reference to the movements and fusion of the palatine processes. Acta. Anat, 68: 473-508.

Arey, L.B. (1974): Developmental anatomy. A text book and laboratory manual of embryology. Revised 7th ed. W. B. Saunders Company Philadelphia and London.

Beaudoin, S.; Barbet, P. and Bargy, F. (2003): Developmental stages in the rabbit embryo: guidelines to choose an appropriate experimental model. Fetal. Diagn. Ther. Karger AG, Basel, 18:422-427.

Burk, D.; Sadler, T.W. and Langman, J. (1979): Distribution of the surface coat material on the nasal folds of mouse embryos as demonstrated by concanavaline a binding. Anat. Rec., 193: 185-196.

Cheville, N.F. and Stasko, J. (2014): Techniques in Electron Microscopy of Animal Tissue. Veterinary Pathology, 51(1):28-41. Doi: $10.1177 / 0300985813505114$. 
Cuschieri, A. and Bannister, L.H. (1975): The development of the olfactory mucosa in mouse light microscopy. J. Anat. 119(2):277-286.

Drury, R.A.B. and Wallington, E.A. (1980): Carleton's histological technique. Fifth Ed. Oxford University. USA.

Carlson, B.M. (1981): Patten's Foundations of Embryology 4th. Mc GrawWill Book Company, Pp. 382-390.

Frandson, R. D., Lee Wilke W. and Fails, A. D. (2009) Anatomy and physiology of farm animals. A John Wiley \& Sons, Inc., Publication Seventh edition, US, 51:58.

Gaara, J.D. (1976): Cell degeneration during the fusion of the nasal processes in mice. Anat. Record, 184:407.

Gaara, J.D. and Langman, J. (1977): Fusion of the nasal swelling in the mouse embryo: regression of the nasal fin. J. Anat., 150:477-500.

Kumoi T., Nishimura, Y. and Shiota, k. (1993): The embryologic development of the human anterior nasal apreture. Acta Otolaryngol, 113(1): 93-97.

McGeady, T. A.; Quinn, P. J.; Fitz Patrik, E. S.; Ryan, M. T.; Kilroy, D.; and Lonergan, P. (2017): Veterinary Embryology. John Wiley \& Sons, Ltd, second edition, U.K. Pp 232-240, SBN: 9781118940617.
McGrath, P. (1980): Findings in human cyclopia with reference to the development of the nasal cavity. J. Anat. Proceeding of Anatomical Society of Australia and New Zealand. 130(1):211.

Müller F. and O'Rahilly R. (2004): Olfactory structures in staged human embryos. Cells tissues organs karger AG, Basel,178:93-116.

Mayor, R. and Theveneau E. (2013): The neural crest. Development, the Company of Biologists Ltd., 140: 2247-2251.

Nishimura, Y. (1993): Embryological study of nasal cavity development in human embryos with reference to congenital nostril atresia. Acta. Anat., 147(3):140-144.

Noden, D.M. and De Lahunta, A. (1985): The embryology of domestic animals developmental mechanisms and malformations. Williams and Wilkins Baltimore and London. Pp. 161170.

\section{Nomina Anatomica Veterinaria} (2017): International committee on veterinary gross anatomical Nomenclature. General Assembly of the World Association of Veterinary Anatomists, 6th Ed., Hannover (Germany), Columbia, MO (U.S.A.), Ghent (Belgium), Sapporo (Japan).

Nomina Embryologica Veterinaria (2017): International Committee on 
Prenatal nostril development in rabbit

Veterinary Embryological Nomenclature (ICVEN.). General Assembly of the World Association of Veterinary Anatomists (WAVA.) Knoxville, TN (U.S.A.) 2003, 2th Ed., Ghent (Belgium).

Nomina Histologica Veterinaria (2017): International committee on veterinary Histological Nomenclature (ICVHN). General Assembly of the world association of veterinary anatomists, 2018 by the General Assembly of the WAVA. 1stEd., Hannover (Germany), Columbia, MO (U.S.A.), Ghent (Belgium), Sapporo (Japan).

Roongruangchai, J.; Pilakasiri, K. and Imjai, S. (2006): Development of the Face, Siriraj Med J.58:716-719.

Sadler, T. W. (2012): Langman's Medical Embryology., Lippincott Williams and Wilkins Baltimore and Philadelphia12 ${ }^{\text {th }}$ edition, Pp. 268:285, ISBN 978-1-4511-1342.

Seham-Gabr, S.H. (2015): Some anatomical studies on the development of the nasal cavity and its related structures in the white New Zeeland rabbit. Ph.D. Thesis. Anat. and Emb. Depart. Faculty of Vet. Med.- Sadat City University.

Shaproi, B.L. (1970): Enzyme histochmistry of embryonic nasal mucosa. Anat. Rec., 166: 87-98.

Snell, R. S. (1975): Clinical embryology for medical students 2nd Ed. Little brown company Boston.
Alomaisi et al.,

Som, P.M. and Naidich, T. P. (2013): Illustrated Review of the Embryology and Development of the Facial Region, Part 1: Early Face and Lateral Nasal Cavities. Ajnr. Am. J. Neuroradiol, 34:2233- 40. http://dx.doi.org/10.3174/ajnr.

A3415. Ebook ISBN: 978-0-70205032-9.

Suvarna, S.K., Layton, c. and Bancroft, J.D. (2013): Bancroft's theory and practical of histological techniques. Seventh ed, Elsevier. Churchill Livingstone, UK.

Valverde, F.; Santacana, M. and Heredia, M. (1992): Formation of an olfactory glomerulus: morphological aspects of development and organization. Neuroscience, 49(2): 255 275.

Vidic, B. (1971): The prenatal morphogenesis of the lateral nasal wall in the rat (Mus rattus). J. Morphol., 133: 303-318.

Vidic, B.; Greditzer, H.G and Litchy, W.J. (1972): The structure and prenatal morphogenesis of the nasal septum in the rat. J. Morphol. 137:131-148.

Warbrick, J.G. (1960): The early development of the nasal cavity and the upper lip in the human embryo.J.Anat.94:351-362.

Corresponding author:

Saleh Ahmed M. A. ALomaisi

Email: elemesy18@vet.zu.edu.eg

Tel: 00201154480020 \& Fax: +20552283683 

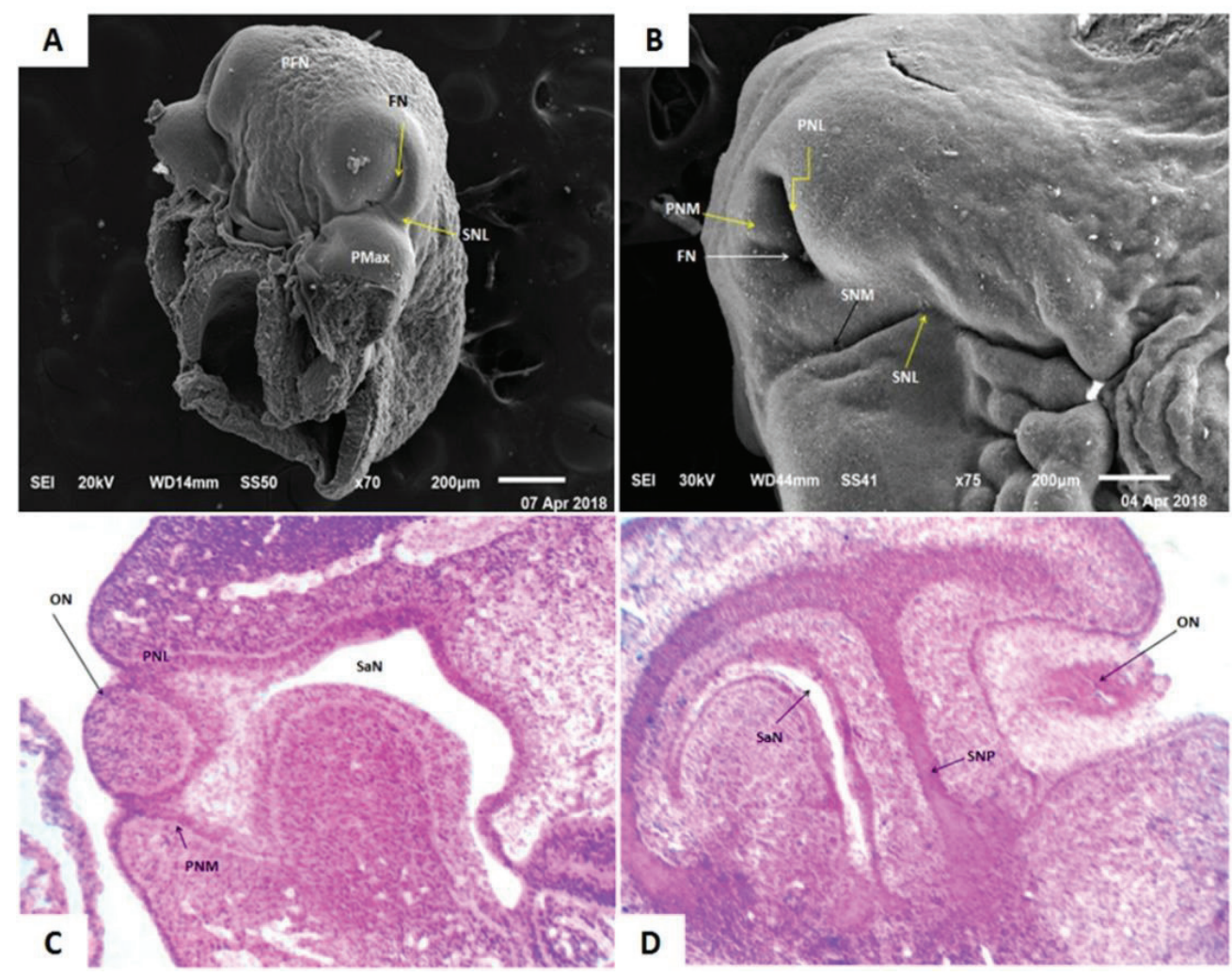

Fig (1):

A- A photomicrograph of scanning electron micrograph (SEM) of the head of 11-days-old rabbit embryo showing; the nasal placodes as a Fovea nasalis (FN), Prominentia frontonasalis (PFN), Processus maxillaris (PMax), Sulcus nasomaxillaris (SNL).

B- A scanning electron micrograph (SEM) of head of 12-days-old rabbit embryo showing; prominentia Fovea nasalis (FN), nasalis lateralis (PNL), Prominentia nasalis medialis (PNM), Sulcus nasolacrimalis (SNL) and Sulcus nasomaxillaris (SNM).

C- A photomicrograph of L. S. of the head of 12-days-old rabbit embryo showing; Obturaculum nasalis (ON), Saccus nasalis (SaN), Prominentia nasalis lateralis (PNL) and Prominentia nasalis medialis (PNM). (H.E. stain. 100X).

D- A photomicrograph of C. S. of the head of 12-days-old rabbit embryo showing; Obturaculum nasalis (ON), Saccus nasalis (SaN), appearance of the Septum nasi primitive (SNP). (H.E. stain. 100X). 

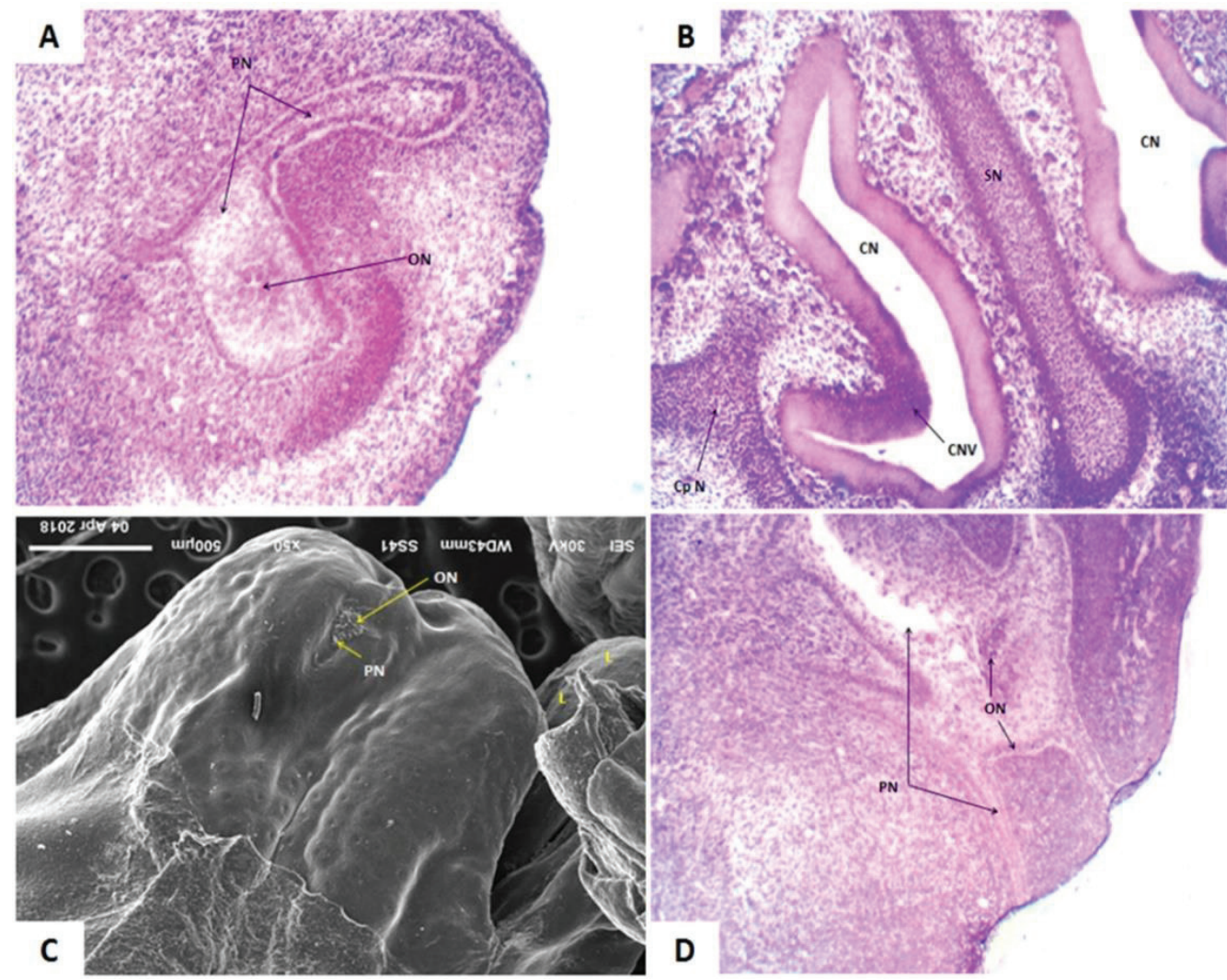

Fig. (2)

A- A photomicrograph of L. S. of the head of a 13-days-old rabbit embryo showing; primitive of nostril (PN) still closed with Obturaculum nasalis (ON). (H.E. stain. 100X).

B- A photomicrograph of C. S. of the head of a 13-days-old rabbit embryo showing; the primitive Cavum nasi (CN), Septum nasi (SN), primordia of Concha nasalis ventralis (CNV) and primordia of Capsula nasalis primitivae $(\mathrm{CpN})$. (H.E. stain. 100X).

C- A scanning electron micrograph (SEM) of the head of a 16-days-old rabbit Embryo showing; the primordia of nostril(PN) occluded with epithelial Obturaculum nasalis $(\mathrm{ON})$ and lingua $(\mathrm{L})$.

D- A photomicrograph of L. S. of the head of a 16-days-old rabbit embryo showing; the cellular degeneration in the center of Obturaculum nasalis $(\mathrm{ON})$, of primordia of nostril (PN) marked by the appearance of irregular and numerous piknotic nuclei. (H.E. stain. 400X). 


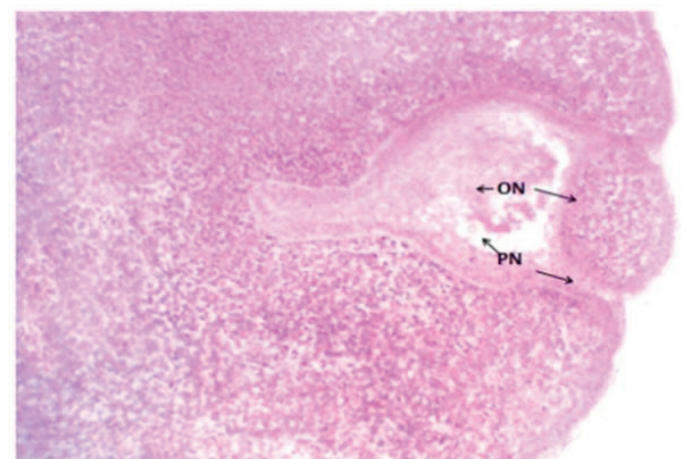

A
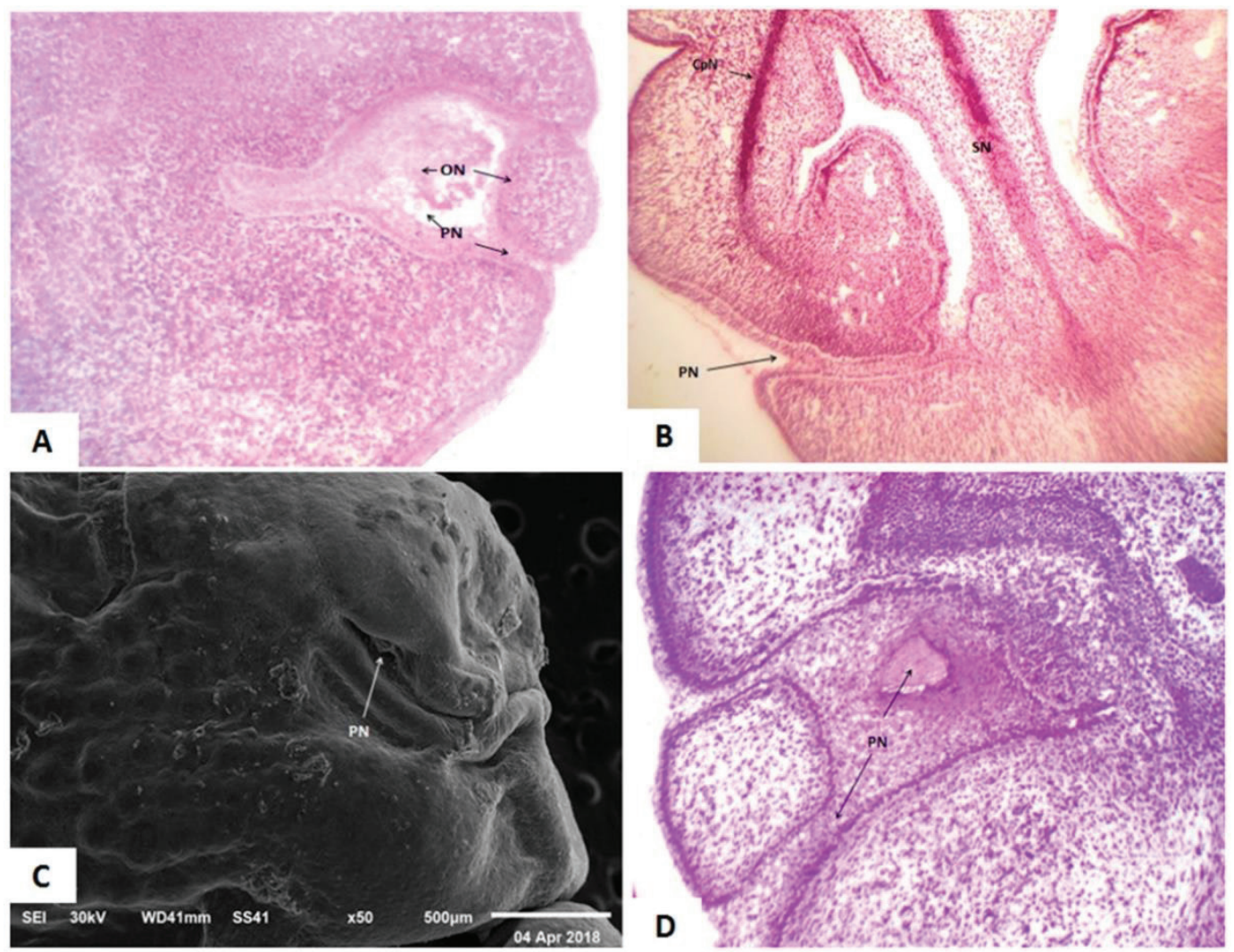

Fig. (3)

A photomicrograph of L. S. of the head of a 18-days-old rabbit fetus showing; the center of Obturaculum nasalis $(\mathrm{ON})$, was disoluted and the primordial of nostril (PN) was began to canalized. (H.E. stain 400X).

A- A photomicrograph of C. S. of the head of a 18-days-old rabbit fetus showing; the primordial of nostril (PN), Septum nasi (SN), Capsula nasalis primitivae (CpN). (H.E. stain 40X).

B- A scanning electron micrograph (SEM) of the head a 20-days-old rabbit fetus showing; the nasal plug was desolated and the nostril (PN) were canalized centrally.

C- A photomicrograph of L. S. of head of a 20-days-old rabbit fetus showing; the nasal plug was desolated and the nostril (PN) were canalized centrally. (H.E. stain 400X). 

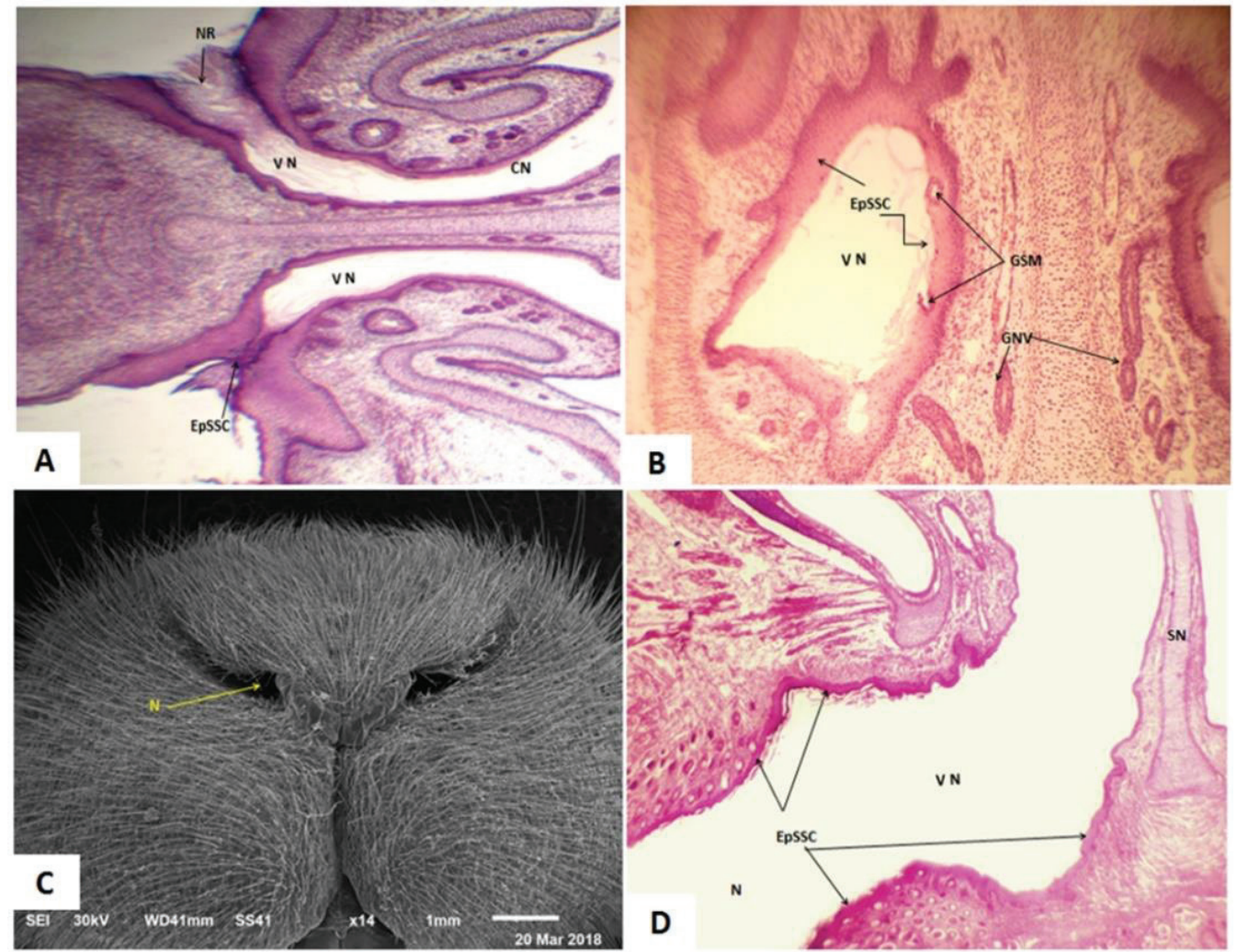

Fig. (4)

A- A photomicrograph of C. S. of head of a 22-days-old rabbit fetus showing; Nares rostralis (NR) covered by Epithelium stratificatum squamosum cornificatum (EpSSC) with keratohyaline granules which were present in the most superfacial layer specially in covering epithelium of the rostral part of Vestibulum nasi (VN), Cavum nasi (CN). (H.E. stain 40X).

B- A photomicrograph of C. S. of head a 22-days-old rabbit fetus old showing; Vestibulum nasi (VN) lined by thick Epithelium stratificatum squamosum cornificatum (EpSSC), Glandula nasalis vestibulum (GNV) and Glandula submucosum (GSM). (H.E. stain 100X).

C- A scanning electron micrograph (SEM) of the head a 30-days-old rabbit fetus showing; the right and left nostril $(\mathrm{N})$ were clear formation and opened resemble postnatal.

D- A photomicrograph of C. S. of the head of a 30-days-old rabbit fetus showing; Vestibulum nasi (VN) was lined by Epithelium stratificatum squamosum cornificatum (EpSSC), Septum nasi (SN). (H.E. stain 40X).

E- Please do the same as in figs 1,2 